Int. J. Dev. Biol. 62: 641-645 (2018)

https://doi.org/10.1387/ijdb.180023js

\title{
The folic acid metabolism gene mel-32/Shmt is required for normal cell cycle lengths in Caenorhabditis elegans
}

\author{
KALIN D. KONRAD, RAQUEL A. CAMPBELL, VANESSA THIEL and JESSICA SULLIVAN-BROWN* \\ Department of Biology, West Chester University of Pennsylvania, West Chester, PA, USA
}

\begin{abstract}
Neural tube defects are common and serious birth defects in which the brain and/or spinal cord are exposed outside the body. Supplementation of foods with folic acid, an essential vitamin, is linked to a lower risk of neural tube defects; however, the mechanisms by which folic acid influence neural tube defect risk are unclear. Our research seeks to identify the basic cellular roles of known folic acid metabolism genes during morphogenesis using the roundworm Caenorhabditis elegans (C. elegans) as a simple model system. Here, we used live imaging to characterize defects in embryonic development when mel-32 is depleted. mel-32 is an essential folic acid metabolism gene in $C$. elegans and a homolog to the mammalian enzyme serine hydroxymethyltransferase (Shmt). Disruption of mel-32 resulted in a doubling or tripling of cell cycle lengths and a lack of directed cell movement during embryogenesis. However, the order of cell divisions, as determined by lineage analysis, is unchanged compared to wild type embryos. These results suggest that mel$32 / \mathrm{Shm}$ is required for normal cell cycle lengths in $C$. elegans.
\end{abstract}

KEY WORDS: folic acid, Shmt, mel-32, C. elegans, cell cycle

The neural tube is an embryonic structure that gives rise to the brain and spinal cord. Failure of neural tube closure results in neural tube defects, in which part of the brain and/or spinal cord is exposed outside the skin. Neural tube defects, like spina bifida, are a leading cause of birth defects, which can be fatal or result in lifelong disabilities. Folic acid fortification and supplementation is widely recognized to decrease the risk of neural tube defects (Greene and Copp, 2014). Folic acid fortification of certain grain food products, like breakfast cereals, was mandated by the FDA in the late 1990's and has decreased the rates of neural tube defects between 10-80\%, depending on the location and study (Imbard et al., 2013). Despite this strong correlation between folic acid and neural tube defect risk, the roles of folic acid during neural tube development are poorly understood (Blom et al., 2006; Wallingford et al., 2013).

In this study, we used the roundworm Caenorhabditis elegans (C. elegans) as a simple model system to study how folic acid metabolism genes affect early embryogenesis. Although $C$. elegans lack a neural tube, cell behaviors that occur during neural tube closure, such as actomyosin dependent apical constriction, are utilized during morphogenesis in C. elegans (Sawyer et al., 2011). C. elegans are advantageous for this study because they are optically transparent, allowing for cells to be easily visualized in vivo, and they are amenable to genetic studies. Importantly, $C$. elegans have a functional folic acid metabolism pathway (Austin et al., 2010; Balamurugan et al., 2007; Cabreiro et al., 2013; Chaudhari et al., 2016; Ortbauer et al., 2016; Virk et al., 2016) allowing hypotheses to be built concerning the roles of folic acid metabolism genes during morphogenesis across species.

Serine hydroxymethyltransferase (Shmt) is a folic acid metabolism gene that catalyzes the reversible conversion of serine to glycine, generating the one-carbon unit 5,10 methylenetetrahydrofolate (5,10-methylene THF), which is then used in the de novo synthesis of thymidylate (dTMP) from deoxyuridylate (dUMP) (reviewed in (Chon et al., 2017). Despite the important roles of Shmt in the folic acid metabolism pathway, mutations in mice that knockout the cytoplasmic form of Shmt (Shmt1), result in viable and fertile offspring, presumably due to the redundant functions of Shmt2a (MacFarlane et al., 2008). However, if mice with decreased levels of Shmt1 are fed a folate deficient diet, a neural tube defect known as exencephaly was observed (Beaudin Abbreviations used in this paper: C. elegans, Caenorhabditis elegans; mel-32, maternal
effect lethal-32; MZ, maternal zygotic; Shmt, Serine hydroxymethyltransferase.

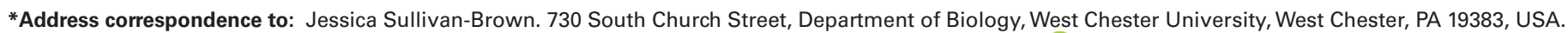
Tel: (610) 436-2864. E-mail: jsullivan@ wcupa.edu - web: http://darwin.wcupa.edu/faculty/sullivan-brown - iD https://orcid.org/0000-0001-9759-3014
}

Supplementary Material (one movie) for this paper is available at: https://doi.org/10.1387/ijdb.180023js

Submitted: 11 January, 2018; Accepted: 2 August, 2018.

ISSN: Online 1696-3547, Print 0214-6282

(C) 2018 UPV/EHU Press

Printed in Spain 
A

Time-lapse images

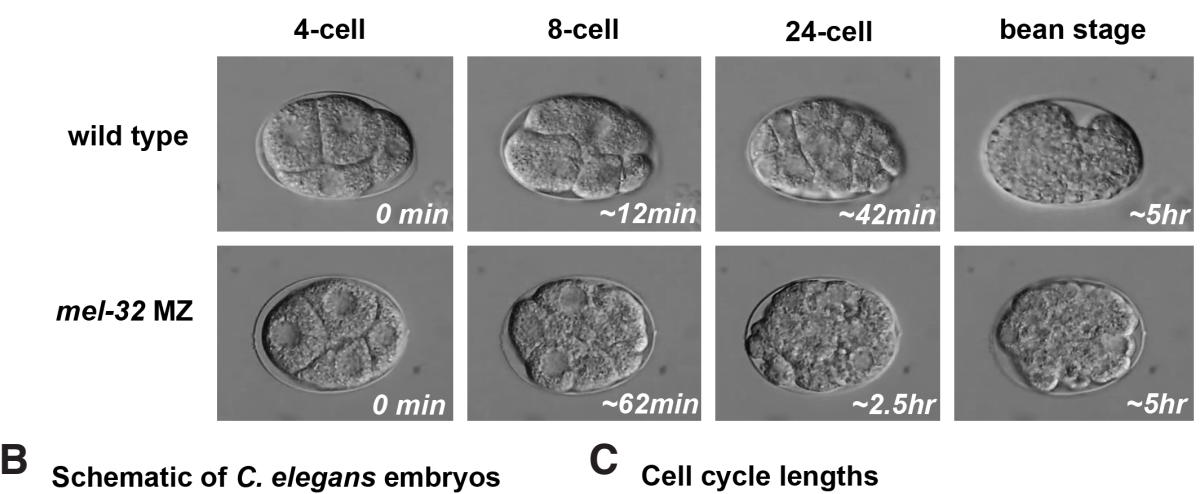

4-cell

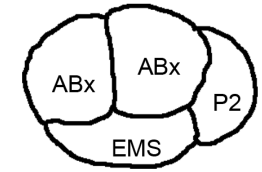

8-cell

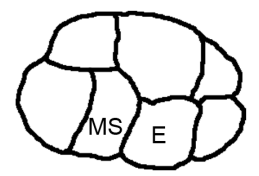

Fig. 1. Cell cycle lengths are increased in mel-32 maternal zygotic (MZ) embryos. (A) Representative images from time-lapse recordings of wild type and mel-32 MZ embryos over the course of $\sim 5$ hours of development. The 4-cell, 8-cell, 24 cell-stages, and bean stages are shown. Omin=beginning of time-lapse, min=minutes, hr=hours. (B) Schematic of wild type C. elegans embryos, illustrating the positions of the $A B x, E M S, P 2, M S$ and E cells. (C) Quantification of cell cycle lengths of early cell divisions for the ABX, EMS, P2, MS and E cells. Green and orange bars represent wild type and mel-32 MZ embryos respectively. For each cell division, the length of the cell cycle is significantly increased in mel-32 MZ embryos compared to wild type (student's t-test, $p<.05$ ); WT( $n=4)$, mel-32 MZABX) EMS/P2 (n=3), mel-32 MZ MS and E (n=4)). Error bars represent standard error of means. from mel-32(s2518) homozygous null parents as mel-32 MZ embryos. To better understand the developmental roles of mel-32/Shmt, we used in vivo time-lapse imaging to analyze the developmental defects in mel-32MZembryos. In our initial analysis, we noticed that mel-32 $\mathrm{MZ}$ embryos required more time to transition from the 4-cell, 8-cell and 24-cell stages. As shown in Fig. 1A, the transition from the 4- to 24-cell stage in wild type embryos normally requires about 40 minutes to complete. However, in mel-32 MZ embryos, these stages took upwards of 2.5 hours to complete. By a little over 5 hrs of development after the 4-cell stage, wild type embryos exhibited extensive cell movements that comprise the gastrulation and epidermal enclosure stages (Chisholm and Hardin, 2005). During gastrulation, endoderm, mesoderm, neural and germ-cell precursors become internalized (Harrell and Goldstein, 2011; Nance et al., 2005) and during epidermal enclosure, epithelial cells surround the embryo (Chisholm and Hardin, 2005). After epidermal enclosure, the wild type embryo takes on a characteristic "bean-shape" as the process of elongation begins (Fig. 1A, Supplementary Movie1). In mel-32 MZ embryos, morphogenesis failed and even after 5 hours of development, the embryo remained amorphous with no evidence of directed cell movements (Fig. 1A, Supplementary Movie1).

To better understand the developmental defects in mel-32 MZ embryos, we analyzed cell cycle lengths in the AB cells (ABx), EMS, $P 2, M S$ and $E$ cells (schematic of cell positions shown in Fig. 1B). We observed striking increases in cell cycle lengths in mel-32 MZ embryos, with lengths nearly double or triple the normal cell cycle length (Fig. 1C, Table et al., 2011). Furthermore, if Shmt1 deficient mice are bred into the splotch mutant $\left(P a x 3^{s p}\right)$, a mutant previously shown to have impaired de novo synthesis of dTMPs, the incidence and severity of neural tube defects increased (Beaudin et al., 2011).

The $C$. elegans homolog of Shmt was previously identified as mel-32 (maternal effect lethal-32) and shown to be essential during early embryogenesis (Vatcher et al., 1999; Vatcher et al., 1998). We provide evidence that mel-32/Shmt is essential for normal cell-cycle lengths but is not required in determining the order of cell divisions.

\section{Results}

\section{mel-32/Shmt is required for normal cell cycle lengths of early embryonic cell divisions}

mel-32(s2518) is a maternal zygotic (MZ) mutation that results in embryonic arrest at or before the 100 cell stage, a phenotype which can be rescued with genomic SHMT DNA (Vatcher et al., 1998). For simplicity and consistency, we will refer to embryos
1). The cell cycle length defects were not confined to a specific cell lineage, as cells that give rise to the muscle and neurons (MS and $A B$ ), endoderm (E), and germline (P2) all showed significant increases in cell cycle lengths. These data suggest that mel-32/ Shmt is required for normal cell cycle progression in $C$. elegans.

To control for the possibility that the $d p y-17(e 164)$ mutation, present in the mel-32(s2518) genetic strain as a phenotypic marker, is affecting the cell cycle, we analyzed cell cycle lengths in the BC5078 strain, which carries the $d p y$-17(e164) mutation only. $d p y-17$ is a cuticle collagen gene that results in short/stubby worms (Page and Johnstone 2007), but does not have a known role in the cell cycle. Our data indicate there was no defect in cell cycle length in $d p y-17($ e164) mutant embryos (Table 1), suggesting that the presence of the $d p y$-17(e164) mutation in the mel-32(sz518) strain does not cause cell cycle defects. Attempts to disrupt mel-32 using an RNAi-by-feeding approach resulted in a weaker embryonic lethality phenotype compared to mel-32 MZ embryos. Further, early cell divisions in mel-32(RNAi) embryos did not show a cell cycle defect (Table 1). We hypothesize that the RNAi-by-feeding approach resulted in an incomplete knockdown 


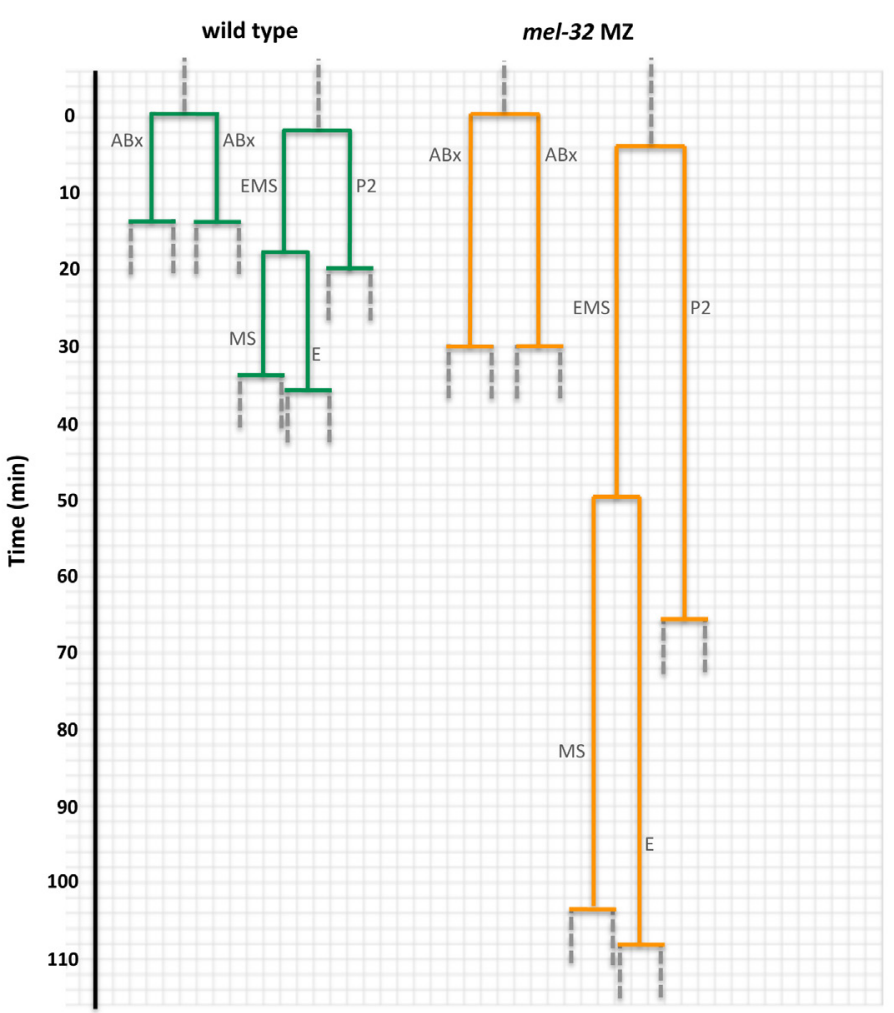

Fig. 2.The order of early cell divisions is not affected in mel-32 maternal zygotic (MZ) embryos. Time-lapse microscopy was used to determine the order of cell divisions, represented as an embryonic cell lineage diagram. Green and orange solid lines indicate cell divisions from wild type $(n=4)$ and mel-32 MZ embryos ( $n=4)$ respectively. Gray dotted lines indicate cells that divided but the length of the cell cycle is not represented. Time in minutes is indicated on the $y$-axis.

of mel-32; however, we cannot rule out a possible synergistic effect between mel-32 and $d p y-17$ knockouts.

mel-32/Shmt is not required for the order of cell divisions

We next asked if the order of cell divisions was affected in mel-32 MZ embryos. In C. elegans the order of each cell division is known and highly invariant (Sulston et al., 1983). To determine the order of cell divisions, we constructed lineage tracings of each cell division, until the division of the MS and E cells. Surprisingly, although the length of each cell cycle is increased significantly, the order in which the cells divide is normal (Fig. 2). These data indicate that while mel-32/Shmt has important roles in determining the length of the cell cycle, it is dispensable for determining the order of cell divisions, unlinking these processes.

\section{Discussion}

In this report, we used the roundworm $C$. elegans as a simple system to better understand how mel-32/Shmt, a folic acid metabolism gene, affects cell behaviors during development. We showed that defects in mel-32 resulted in significantly increased cell cycle times in the early $C$. elegans embryo. Interestingly, mutations in folt-1, the $C$. elegans homolog of the folate transporter RFC, may also result in cell proliferation defects suggested by a reduced germline with less sperm and defective oocytes (Austin et al., 2010). The specific phase of the cell cycle affected in mel-32 MZ mutants is unknown; however, previous data have indicated that folate deficiencies can arrest cells in S phase (Courtemanche et al., 2004). Since the cell divisions analyzed in this study are primarily composed of $\mathrm{S}$ and $\mathrm{M}$ phases (Bao et al., 2008; Edgar and McGhee, 1988), we predict that $S$ phase is affected in mel-32 MZ mutants, possibly by decreasing the rate of DNA replication through a reduction of dTMP levels. Alternatively, S phase may be stalled due increased DNA repair. In mammals, reduced levels of nuclear Shmt 1 increased the prevalence of DNA nicks and double-stranded breaks resulting in genomic instability (Anderson and Stover, 2009; Blount et al., 1997; MacFarlane et al., 2008; Wilson et al., 2014). In addition, chromosomal breakage has also been observed in humans with folate deficiencies (Blount et al., 1997). Future work will be needed to determine if lack of mel-32/Shmt results in DNA damage which may slow the cell cycle in $C$. elegans.

Although the cell cycle was significantly lengthened, the order of early embryonic cell divisions was unaffected in mel-32 MZ embryos. Conditions that slow the cell cycle in $C$. elegans, such as a temperature decrease, or mutations that cause an overall slowing of development (ie, the clk-1 gene), also result in a lengthening of the cell cycle while maintaining the relative order of cell divisions (Nair et al., 2013). Although the mechanisms that establish the highly invariant order of cell divisions remain unclear, evidence indicates that cell fate plays an important role (Bao et al., 2008).

It will be important to analyze the expression of cell fate molecular markers to determine if there is evidence of cell differentiation during these early cell divisions in mel-32 MZ embryos.

\section{Materials and Methods}

\section{C. elegans strains and worm maintenance}

C. elegans were cultured and handled as described in (Brenner, 1974). All strains were maintained at $20^{\circ} \mathrm{C}$ with OP50 E. coli as its food source. The following strains were used in this study: WT Bristol N2, BC5078 dpy-17(e164), mel-32(s2518), unc-32(e189)III;sDp3 (III;f); CB164 $d p y-17(e 164)$.

TABLE 1

\section{CELL CYCLE LENGTHS}

\begin{tabular}{|c|c|c|c|c|c|}
\hline & $A b x$ & EMS & P2 & MS & $\mathbf{E}$ \\
\hline & mean \pm SEM & mean \pm SEM & mean \pm SEM & mean \pm SEM & mean \pm SEM \\
\hline WT & $13.58 \pm 0.44(n=4)$ & $15.98 \pm 0.33(n=4)$ & $18.40 \pm 0.28(n=4)$ & $16.25 \pm 0.55(n=4)$ & $17.58 \pm 0.42(n=4)$ \\
\hline$m e l-32 \mathrm{MZ}$ & $30.89 \pm 1.28^{\star}(n=3)$ & $46.89 \pm 3.77^{\star}(n=3)$ & $62.66 \pm 7.08^{*}(n=3)$ & $54.25 \pm 9.96^{\star}(n=4)$ & $58.33 \pm 9.37^{\star}(n=4)$ \\
\hline mel-32(RNAi) & $12.55 \pm 0.22(n=3)$ & $13.77 \pm 0.29(n=3)$ & $17.31 \pm 0.35(n=3)$ & $16.25 \pm 0.21(n=4)$ & $17.08 \pm 0.34(n=4)$ \\
\hline dpy-17(e164) & $13.22 \pm 0.62(n=3)$ & $14.55 \pm 0.67(n=3)$ & $17.66 \pm 1.20(n=3)$ & $16.22 \pm 1.24(n=3)$ & $17.88 \pm 1.35(n=3)$ \\
\hline
\end{tabular}

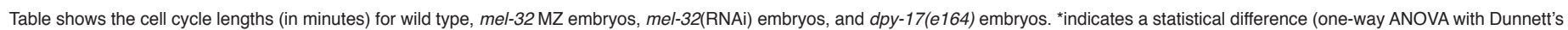
post test, $p<.05$ ). 


\section{RNA interference (RNAi)}

RNAi-by-feeding was performed using a protocol outlined previously (Sawyer et al., 2011; Sullivan-Brown et al., 2016) with minor modifications. Three to five L4 larvae from the N2 wild type background were placed on RNAi plates seeded with double-stranded RNA(dsRNA) producing bacterial strains as in (Kamath et al., 2001; Timmons and Fire, 1998). RNAi plates were either made in-house (standard Nematode Growth Media (NGM) plates, with $25 \mu \mathrm{g} / \mathrm{ml}$ of Carbenicillin and $1 \mathrm{mM} \mathrm{IPTG)} \mathrm{or} \mathrm{purchased} \mathrm{directly}$ from LabExpress (\#5003-60). RNAi bacterial feeding strains were obtained from a dsRNA feeding library from the Medical Research Council (MRC) Geneservice (Kamath and Ahringer, 2003) and generously supplied by the Goldstein lab-UNC Chapel Hill.

\section{Microscopy}

C. elegans embryos were mounted on poly-L-lysine coated coverslips at the one or four-cell stage and mounted on a $2.5 \%$ agarose pad made with M9 buffer (as in Sawyer et al., 2011). Differential inference contrast (DIC) imaging was performed on an Olympus BX60 Upright Microscope. All time-lapse recordings were taken on a Celestron Digital Microscope imager HD 5MP and recorded using free time-lapse imaging software by VideoVelocity Time-Lapse Capture Studio. Time-lapse images were taken every 20 seconds, with manual focusing. All images were acquired with a 40x objective. Supplementary Movie 1 is shown at 25 frames per second.

\section{Quantification of cell cycle lengths and lineage analysis}

Time-lapse video recordings (as described above) were used to determine the cell cycle lengths by tracking the cell divisions of the ABx, P2, EMS, E, and MS cells as shown in lineage tracings from (Sulston et al., 1983). Cell division was measured from the birth of the precursor cell to the birth (end of cytokinesis) of its daughters. Depending on the analysis, a student's t-test or one-way ANOVA with Dunnett's post test was used to determine statistical significance $(p<.05)$. Lineages tracings were generated in Microsoft PowerPoint using average cell cycle lengths from wild type and mel-32 MZ embryos.

\section{Acknowledgements}

We thank our colleagues, especially Jennifer Tenlen, Jennifer Heppert and Jodi Schottenfeld-Roames for their critical reading, suggestions, and comments on this manuscript. We also thank Gerry Misquith for her help in obtaining lab materials. Strains were provided by the Caenorhabditis elegans Genetics Center, which is funded by the National Institutes of Health Office of Research Infrastructure Programs (P40 OD010440). This work was supported by the generosity of West Chester University's Alumni \& Foundation Center, the College of the Sciences and Mathematics at West Chester University and the Georgann Cullen Award. JSB would like to thank the many undergraduates at West Chester University that had contributions to this project and the Department of Biology at WCU for support.

\section{References}

ANDERSONDD, STOVERPJ (2009). SHMT1 and SHMT2 are functionally redundant in nuclear de novo thymidylate biosynthesis. PLoS One 4: e5839.

AUSTIN MU, LIAU WS, BALAMURUGAN K, ASHOKKUMAR B, SAID HM, LAMUNYON CW (2010). Knockout of the folate transporter folt-1 causes germline and somatic defects in C. elegans. BMC Dev Biol 10: 46.

BALAMURUGAN K, ASHOKKUMAR B, MOUSSAIF M, SZE JY, SAID HM (2007). Cloning and functional characterization of a folate transporter from the nematode Caenorhabditis elegans. Am J Physiol Cell Physiol 293: C670-681.

BAO Z, ZHAO Z, BOYLE TJ, MURRAY JI, WATERSTON RH (2008). Control of cell cycle timing during C. elegans embryogenesis. Dev Biol 318: 65-72.

BEAUDIN AE, ABARINOV EV, NODEN DM, PERRY CA, CHU S, STABLER SP, ALLEN RH, STOVER PJ (2011). Shmt1 and de novo thymidylate biosynthesis underlie folate-responsive neural tube defects in mice. Am J Clin Nutr 93: 789-798.

BLOM HJ, SHAW GM, DEN HEIJER M, FINNELL RH (2006). Neural tube defects and folate: case far from closed. Nat Rev Neurosci 7: 724-731

BLOUNT BC, MACK MM, WEHR CM, MACGREGOR JT, HIATT RA, WANG G, WICKRAMASINGHE SN, EVERSON RB, AMES BN (1997). Folate deficiency causes uracil misincorporation into human DNA and chromosome breakage: implications for cancer and neuronal damage. Proc Natl Acad Sci USA 94: 3290-3295.

BRENNER S (1974). The genetics of Caenorhabditis elegans. Genetics 77: 71-94.

CABREIRO F, AU C, LEUNG KY, VERGARA-IRIGARAY N, COCHEME HM, NOORI T, WEINKOVE D, SCHUSTER E, GREENE ND, GEMS D (2013). Metformin retards aging in $C$. elegans by altering microbial folate and methionine metabolism. Cell 153: 228-239.

CHAUDHARI SN, MUKHERJEE M, VAGASIAS, Bi G, RAHMAN MM, NGUYEN CQ, PAUL L, SELHUB J, KIPREOS ET (2016). Bacterial Folates Provide an Exogenous Signal for $C$. elegans Germline Stem Cell Proliferation. Dev Cell38: 33-46.

CHISHOLM AD, HARDIN J (2005). Epidermal morphogenesis. WormBook: 1-22.

CHON J, STOVER PJ, FIELD MS (2017). Targeting nuclear thymidylate biosynthesis Mol Aspects Med 53: 48-56.

COURTEMANCHE C, HUANG AC, ELSON-SCHWAB I, KERRY N, NG BY, AMES $B N$ (2004). Folate deficiency and ionizing radiation cause DNA breaks in primary human lymphocytes: a comparison. FASEB J 18: 209-211.

EDGAR LG, MCGHEE JD (1988). DNA synthesis and the control of embryonic gene expression in C. elegans. Cell 53: 589-599.

GREENE ND, COPPAJ (2014). Neural tube defects. Annu Rev Neurosci37: 221-242.

HARRELL JR, GOLDSTEIN B (2011). Internalization of multiple cells during $C$. elegans gastrulation depends on common cytoskeletal mechanisms but different cell polarity and cell fate regulators. Dev Biol 350: 1-12.

IMBARD A, BENOIST JF, BLOM HJ (2013). Neural tube defects, folic acid and methylation. Int J Environ Res Public Health 10: 4352-4389.

KAMATH RS, AHRINGER J (2003). Genome-wide RNAi screening in Caenorhabditis elegans. Methods 30: 313-321.

KAMATH RS, MARTINEZ-CAMPOS M, ZIPPERLEN P, FRASER AG, AHRINGER J (2001). Effectiveness of specific RNA-mediated interference through ingested double-stranded RNA in Caenorhabditis elegans. Genome Biol2: RESEARCH0002.

MACFARLANE AJ, LIU X, PERRY CA, FLODBY P, ALLEN RH, STABLER SP, STOVER PJ (2008). Cytoplasmic serine hydroxymethyltransferase regulates the metabolic partitioning of methylenetetrahydrofolate but is not essential in mice. J Biol Chem 283: 25846-25853.

NAIR G, WALTON T, MURRAY JI, RAJ A (2013). Gene transcription is coordinated with, but not dependent on, cell divisions during $C$. elegans embryonic fate specification. Development 140: 3385-3394.

NANCE J, LEE JY, GOLDSTEINB (2005). Gastrulation in C. elegans. WormBook: 1-13

ORTBAUER M, RIPPER D, FUHRMANN T, LASSI M, AUERNIGG-HASELMAIER S, STIEGLER C, KONIG J (2016). Folate deficiency and over-supplementation causes impaired folate metabolism: Regulation and adaptation mechanisms in Caenorhabditis elegans. Mol Nutr Food Res 60: 949-956.

PAGE AP, JOHNSTONE IL (2007). The cuticle. WormBook: 1-15.

SAWYER JM, GLASS S, LIT, SHEMER G, WHITE ND, STAROSTINANG, KIPREOS ET, JONES CD, GOLDSTEIN B (2011). Overcoming redundancy: an RNAi enhancer screen for morphogenesis genes in Caenorhabditis elegans. Genetics 188: 549-564.

SULLIVAN-BROWN JL, TANDON P, BIRD KE, DICKINSON DJ, TINTORI SC HEPPERT JK, MESERVE JH, TROGDEN KP, ORLOWSKI SK, CONLON FL, GOLDSTEIN B (2016). Identifying Regulators of Morphogenesis Common to Vertebrate Neural Tube Closure and Caenorhabditis elegans Gastrulation. Genetics 202: 123-139.

SULSTON JE, SCHIERENBERG E, WHITE JG, THOMSON JN (1983). The embryonic cell lineage of the nematode Caenorhabditis elegans. Dev Biol 100: 64-119.

TIMMONSL, FIREA(1998). Specific interference by ingested dsRNA. Nature 395:854

VATCHER GP, BARBAZUK WB, O'NEIL NJ, MARRA MA, HA T, BAILLIE DL (1999). Identification and characterization of a serine hydroxymethyltransferase isoform in Caenorhabditis briggsae. Gene 230: 137-144.

VATCHER GP, THACKER CM, KALETTA T, SCHNABEL H, SCHNABEL R, BAILLIE DL (1998). Serine hydroxymethyltransferase is maternally essential in Caenorhabditis elegans. J Biol Chem 273: 6066-6073.

VIRK B, JIA J, MAYNARD CA, RAIMUNDO A, LEFEBVRE J, RICHARDS SA CHETINA N, LIANG Y, HELLIWELL N, CIPINSKA M, WEINKOVE D (2016). 
Folate Acts in E. coli to Accelerate C. elegans Aging Independently of Bacterial Biosynthesis. Cell Rep 14: 1611-1620.

WALLINGFORD JB, NISWANDER LA, SHAW GM, FINNELL RH (2013). The continuing challenge of understanding, preventing, and treating neural tube defects.
Science 339: 1222002.

WILSON PM, DANENBERG PV, JOHNSTON PG, LENZ HJ, LADNER RD (2014). Standing the test of time: targeting thymidylate biosynthesis in cancer therapy. Nat Rev Clin Oncol 11: 282-298. 


\section{Further Related Reading, published previously in the Int. J. Dev. Biol.}

Regulation of body size in Caenorhabditis elegans: effects of environmental factors and the nervous system Takashi Nagashima, Shoichi Ishiura and Satoshi Suo

Int. J. Dev. Biol. (2017) 61: 367-374

https://doi.org/10.1387/ijdb.160352ss

The SUMO system in Caenorhabditis elegans development

Limor Broday

Int. J. Dev. Biol. (2017) 61: 159-164

https://doi.org/10.1387/ijdb.160388LB

Live imaging reveals spatial separation of parental chromatin until the four-cell stage in Caenorhabditis elegans embryos Jitka Bolková and Christian Lanctôt

Int. J. Dev. Biol. (2016) 60: 5-12

https://doi.org/10.1387/ijdb.150222cl

a integrin cytoplasmic tails have tissue-specific roles during C. elegans development Christopher M. Meighan and Jean E. Schwarzbauer

Int. J. Dev. Biol. (2014) 58: 325-333

https://doi.org/10.1387/ijdb.130327cm

Differences in embryonic pattern formation between Caenorhabditis elegans and its close parthenogenetic relative Diploscapter coronatus

Vera Lahl, Jens Schulze and Einhard Schierenberg

Int. J. Dev. Biol. (2009) 53: 507-515

https://doi.org/10.1387/ijdb.082718vl

A hypothesis linking low folate intake to neural tube defects due to failure of posttranslation methylations of the cytoskeleton

Natalie K. Björklund and Richard Gordon

Int. J. Dev. Biol. (2006) 50: 135-141

https://doi.org/10.1387/ijdb.052102nb

Valproate-induced developmental modifications maybe partially prevented by coadministration of folinic acid and S-adenosylmethionine

NUbeda, EAlonso, J C Martín-Rodríguez, G Varela-Moreiras, J Puerta and J Pérez-Miguelsanz Int. J. Dev. Biol. (1996) 40: S291-S292

http://www.intjdevbiol.com/web/paper/9087803

5 yr ISI Impact Factor $(2016)=2.421$
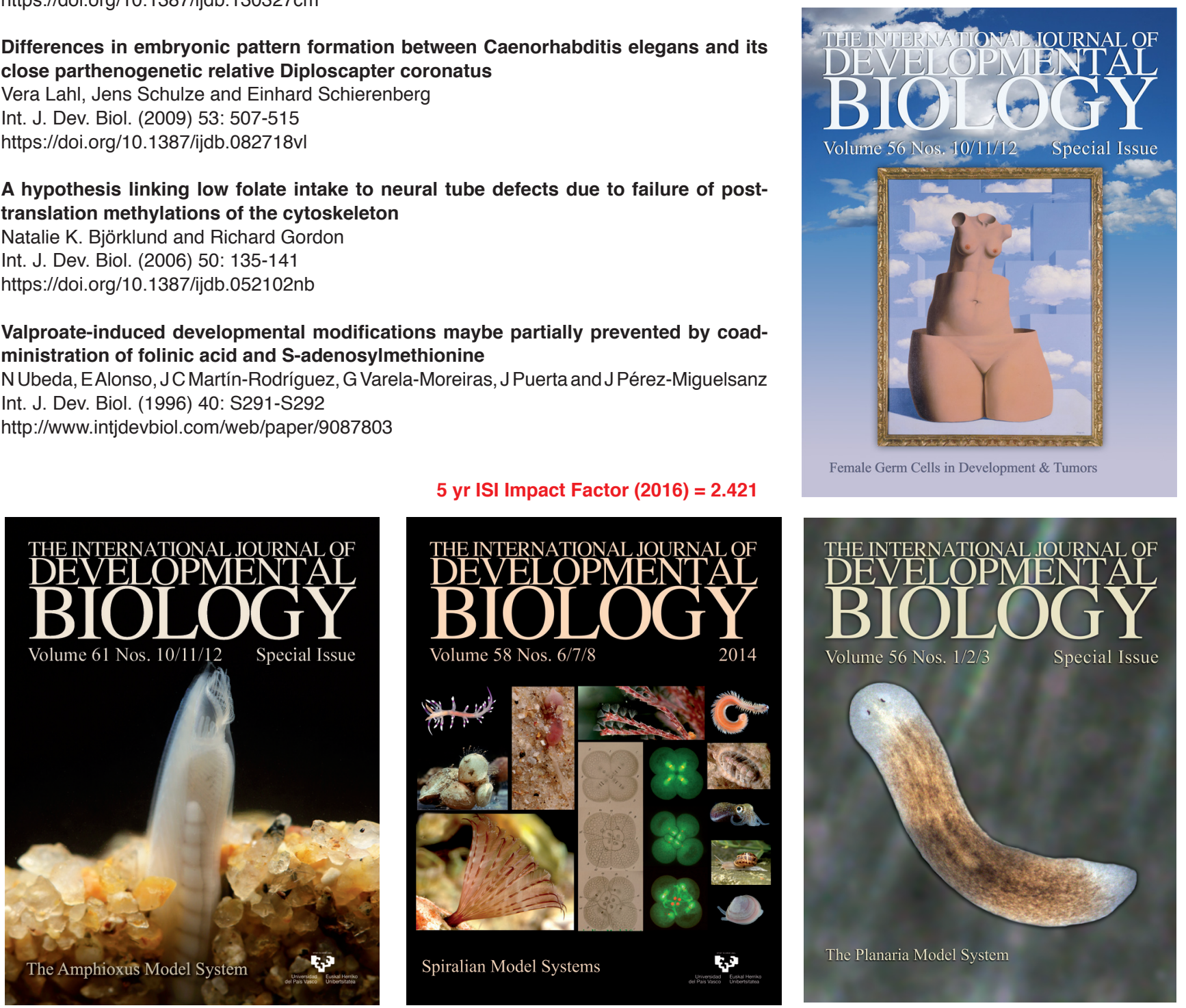